\title{
Eosinophil percentage as a new prognostic marker in patients with ST-segment elevation myocardial infarction undergoing primary percutaneous coronary intervention
}

\author{
AHMET GÜNER ${ }^{1}$, REGAYIP ZEHİR ${ }^{2}$, MACİT KALÇIK ${ }^{3, *}$, ABDULKADIR USLU $^{1}$, \\ ALTUĞ ÖSKEN ${ }^{2}$, ALİ KEMAL KALKAN ${ }^{4}$, EZGİ GÜLTEKİN GÜNER ${ }^{4}$ \\ ${ }^{1}$ Department of Cardiology, Kartal Kosuyolu Training and Research Hospital, Istanbul, Turkey \\ ${ }^{2}$ Department of Cardiology, Siyami Ersek Thoracic and Cardiovascular Surgery Training and Research Hospital, Istanbul, Turkey \\ ${ }^{3}$ Department of Cardiology, Faculty of Medicine, Hitit University, Çorum, Turkey \\ ${ }^{4}$ Department of Cardiology, Mehmet Akif Ersoy Thoracic and Cardiovascular Surgery Training and Research Hospital, Istanbul, Turkey \\ ${ }^{*}$ Corresponding author: Macit Kalçık, MD; Department of Cardiology, Faculty of Medicine, Hitit University, Buharaevler Mah. Buhara 25. Sok. \\ No:1, A Daire:22, Çorum, Turkey; Phone: +90 5364921 789; Fax: +90 3645117 889; E-mail: macitkalcik@yahoo.com
}

(Received: May 13, 2019; Revised manuscript received: July 3, 2019; Accepted: July 8, 2019)

\begin{abstract}
Background: In addition to proinflammatory properties, eosinophils can stimulate platelet activation and enhance prothrombotic pathways. In this study, we aimed to investigate the association between the eosinophil percentage (EOS\%) and major adverse cardiac events (MACE) in patients with ST-segment elevation myocardial infarction (STEMI). Methods: This study enrolled a total of 1,909 patients who were diagnosed with STEMI. Ventricular arrhythmia, reinfarction, the need for cardiopulmonary resuscitation, target vessel revascularization, congestive heart failure, and cardiovascular mortality during index hospitalization were defined as MACE. Results: Three hundred and eighty patients (19.7\%) reached the combined endpoint with MACE. The rates of inhospital mortality and MACE were significantly higher in low EOS\% group as compared to high EOS\% group ( $4 \%$ vs. $1.1 \%, p<0.01$ and $32.8 \%$ vs. $11.3 \%, p<0.01$, respectively). On multivariate logistic regression analyses, EOS\% $(\mathrm{OR}=0.44, p<0.01)$ was found to be one of the independent predictors of MACE. The EOS\% lower than 0.60 on admission predicted inhospital MACE with a sensitivity of $68 \%$ and a specificity of $72 \%$ (AUC: $0.684, p<0.01$ ). Conclusions: Low EOS\% on admission may be associated with high inhospital MACE in STEMI patients. EOS\% may be used as a novel biomarker for risk stratification of these patients.
\end{abstract}

Keywords: complete blood counts, eosinophil percentage, inflammation, major adverse cardiac events, myocardial infarction

\section{Introduction}

Cardiomyocyte necrosis in acute ST-segment elevation myocardial infarction (STEMI) triggers an intense sterile inflammatory response by generating damage-associated molecular signaling $[1,2]$. In order to repair the heart, both local and systemic inflammatory activity including elevated cytokines, activated peripheral leukocytes, and platelets have been documented in patients with STEMI. However, excessive immune feedback may cause harm and markers of inflammation, mainly leukocytes and platelet indices have emerged predictors of adverse clinical outcomes [3]. Although white blood cell counts significantly increase during myocardial infarction, percentage and number of eosinophils (EOSs) decrease in peripheral blood. Rupture of coronary atheroma leading to activation of platelets and thrombus formation is the main mechanism in the pathophysiology of acute STEMI. Besides proinflammatory properties, EOSs stimulate platelet activation and aggregation and enhance prothrombotic pathways by stimulating endothelial cells to expose tissue factor. EOS, platelet, and endothelium interplay are crucial for thrombus formation. EOS promotes platelets and vasculature to proadhesive and prothrombotic phenotype [4]. Hypereosinophilic syndromes result in thrombotic complications with eosinophilic

This is an open-access article distributed under the terms of the Creative Commons Attribution-NonCommercial 4.0 International License, which permits unrestricted use, distribution, and reproduction in any medium for non-commercial purposes, provided the original author and source are credited, a link to the CC License is provided, and changes - if any - are indicated. 
infiltrates [5-8]. Moreover, EOS has been postulated as mediators of thrombosis during acute coronary syndromes. Decreased eosinophil percentage (EOS\%) was related to increased platelet count in STEMI. EOS infiltration has been observed in coronary arterial thrombi. Deposition of EOS in the thrombi where they degraded was the suspected mechanism of EOS\% reduction in peripheral blood [9]. Notably, the decreased EOS $\%$ has been related to serious myocardial damage $[10,11]$. However, prognostic significance of EOS\% has not yet been evaluated in STEMI patients treated with primary percutaneous coronary intervention (PCI). The aim of this study was to investigate the association of EOS\% on admission with major adverse cardiac events (MACE) in patients with STEMI.

\section{Methods}

In this retrospective, single-center, observational clinical study, we evaluated medical records of patients who were admitted to our emergency department with acute STEMI and underwent primary PCI within $12 \mathrm{~h}$ of the onset of symptoms between January 2011 and March 2015. Inclusion criteria included presence of typical ongoing chest pain lasting for $>30 \mathrm{~min}$ and ST elevation of at least $\geq 2 \mathrm{~mm}$ in at least two contiguous leads or new-onset complete left bundle-branch block. The baseline demographic, clinical, and angiographic features and laboratory test results on admission were obtained from hospital files and computer records. Hospital records and state-wide death registry database were analyzed for evaluation of inhospital MACE. Patients with clinical evidence of active cancer, hematological proliferative disorders, hypereosinophilic syndrome, occult or active parasitic infection, chronic inflammatory disease, receiving steroid therapy for autoimmune disease before primary PCI, and patients whose medical records had not been accessed were excluded. Ultimately, 1,909 patients were included in the study. Inhospital MACE was reported as the clinical outcome. The study was approved by the local scientific ethical committee and complied with the Declaration of Helsinki.

Hypertension was defined based on the use of blood pressure-lowering drugs at admission, systolic pressure $>140 \mathrm{mmHg}$ or diastolic pressure $>90 \mathrm{mmHg}$ during measurements. Anemia was defined as baseline hemoglobin levels $<13 \mathrm{~g} / \mathrm{dl}$ in males and $<12 \mathrm{~g} / \mathrm{dl}$ in females. Estimated glomerular filtration rate was calculated using the Modification of Diet in Renal Disease Formula [12]. Patients were considered to have hyperlipidemia if they were being treated with lipidlowering drugs at the time of admission or had abnormal fasting lipid test results according to guidelines [13]. Smoking status was defined based on the current regular use of cigarettes. Patients being treated with glucose-lowering drugs or had a fasting plasma glucose concentration $>7 \mathrm{mmol} / \mathrm{L}$ or a non-fasting plasma glucose concentration $>11.1 \mathrm{mmol} / \mathrm{L}$ were considered to have diabetes mellitus (DM). Contrast-induced nephropathy (CIN) was defined based on either an increase in serum creatinine greater than $25 \%$ or an absolute raise in serum creatinine of $0.5 \mathrm{mg} / \mathrm{dl}$ within $72 \mathrm{~h}$ of administration of radiocontrast [14]. On admission, the clinical status of patients was defined according to the Killip classification [15].

All of PCI procedures were performed either by femoral approach with a $6 \mathrm{~F}$ guiding catheter, and $300 \mathrm{mg}$ chewable aspirin, $600 \mathrm{mg}$ loading dose of clopidogrel on admission, and $70 \mathrm{U} / \mathrm{kg}$ intravenous standard heparin were administered to all patients. Non-ionic, iso-osmolar or non-ionic, low-osmolar contrast media were used. The use of glycoprotein IIb/IIIa receptor blocker (tirofiban) was left to the primary operator's discretion. Occlusion of the infarct-related artery was crossed using a guidewire, direct stenting was implanted whenever possible; in the remaining cases, manuel thrombus aspiration and/or balloon predilatation was carried out. The type of stent used was left to the operator's judgment. If the lesion anatomy was not suitable for stenting, only balloon dilatation was performed. Multivessel disease was described as the presence of $>50 \%$ stenosis in at least two or more major epicardial arteries.

After the procedure, all patients were transferred to coronary intensive care unit and guideline-based cardiac medications were administered at the maximum tolerated doses. A successful intervention was described as a reduction in residual stenosis to $<20 \%$ by balloon angioplasty or successful stent deployment at the desired position with a residual stenosis $<10 \%$ followed by thrombolysis in myocardial infarction grade 3 flow in the infarct-related artery [16]. If could not achieved, it was deemed unsuccessful.

Ventricular arrhythmia (ventricular fibrillation and ventricular tachycardia), reinfarction, the need for cardiopulmonary resuscitation, target vessel revascularization (TVR), congestive heart failure (New York Heart Association functional class $\geq 3$ ), and cardiovascular mortality (unexplained sudden death, death from acute STEMI, heart failure, and arrhythmia) during index hospitalization were regarded as MACE. Reinfarction was defined according to guideline for the universal definition of myocardial infarction [17]. TVR was defined as the need for PCI or surgery due to restenosis or reocclusion of the infarct-related artery.

Echocardiography (Vivid 3 system; General Electric Company, Milwaukee, WI, USA) was performed in all patients after PCI, and left ventricular ejection fraction (LVEF) was calculated from apical four- and two-chamber views using the modified Simpson biplane method.

An antecubital venous blood sample was drawn upon admission to the emergency department from each 
patient before administration of any medication. Complete blood counts, which included hemoglobin, platelets, and all the percentages of white blood cell subtypes (neutrophils, lymphocytes, EOSs, monocytes, and basophils), were analyzed using an automatic blood counter (Cell-dyn 3700; Abbott, Wiesbaden, Germany). C-reactive protein (CRP) levels were measured on Cobas Integra analyzer (Roche Diagnostics, Istanbul, Turkey) using turbidimetric method. Other biochemical parameters including lipid profiles were measured by virtue of commercially available methods and kits. Electronic database of hospital was checked to gather the results.

\section{Statistical analyses}

All statistical analyses were carried out using SPSS statistical software, version 20.0 (SPSS Inc., IBM corp., Chicago, IL, USA). Quantitative variables were presented as mean \pm standard deviation, and qualitative variables were expressed as a percentage. All variables were subjected to Kolmogorov-Smirnov test to assess normality of distribution. Pearson's $\chi^{2}$ test and Fisher's exact test were used to compare dichotomous variables. Student's $t$-test or Mann-Whitney $U$ test were used to compare continuous variables as appropriate. Comparison of multiple mean values was fulfilled using the Kolmogorov-Smirnov test or analysis of variance as appropriate. Spearman's rank test was performed to define the correlations. Multiple logistic regression analysis was carried out to evaluate the independent predictors of inhospital MACE, after correction for baseline confounding factors (clinical and demographic variables with a $p$ value $<0.05$ ), which were entered in the model in block. Hosmer-Lemeshow goodness of fit statistics were used to assess model fit. Receiver operating characteristic (ROC) curves were used to identify the best predictive value of EOS\%. Coefficients with $95 \%$ confidence intervals were presented. A $p$ value $<0.05$ was considered as significant.

\section{Results}

The study population consisted of 1,909 patients who suffered from acute STEMI [male: 1552 (81.3\%), mean age: $54.4 \pm 13.2$ years]. Three hundred and eighty patients $(19.7 \%)$ reached the combined endpoint of MACE in the study population: $45(2.3 \%)$ had reinfarction, $80(4.1 \%)$ had TVR, 139 (7\%) had decompensated heart failure, $33(1.7 \%)$ had ventricular tachycardia and/ or ventricular fibrillation, $39(2 \%)$ had cardiopulmonary arrest, and 47 (2.4\%) died during inhospital follow-up due to cardiac causes. The comparison of the demographic, clinical, and laboratory characteristics of the patients with and without MACE was demonstrated in Table I. Age, the frequency of male sex, hypertension, DM, Killip class 3 or 4, PCI history, CABG history, multivessel disease, unsuccessful PCI, CIN, and CRP were significantly higher in patients with MACE. However, LVEF and $\mathrm{EOS} \%$ were found to be significantly lower in patients with MACE than those without MACE. The ratios of EOS\% to other white blood cell subtypes have also been investigated. However, there was no significant difference between the groups in this regard. In ROC curve analysis, EOS\% lower than 0.60 on admission predicted inhospital MACE with a sensitivity of $68 \%$ and a specificity of $72 \%$ (area under the curve: $0.684 ; p<0.01$ ) (Fig. 1). The study subjects were divided into two groups according to cut-off value of EOS\% derived from ROC analysis. Seven hundred and seventy-three subjects constituted the low EOS\% group (Group 1) and 1,136 subjects were gathered into the high EOS\% group (Group 2). Table II demonstrates the comparison of the demographic, clinical, and laboratory characteristics of the groups. Smoking was more prevalent in the high EOS\% group. On admission, the Killip class of the patients in Group 1 was higher (class 2/3) than those in Group 2. The mean white blood cell count $(p<0.01)$, platelet count $(p<0.01)$, mean platelet volume $(p<0.01)$, and CRP $(p<0.01)$ were significantly higher in Group 1 than Group 2. The patients in Group 1 had worse outcomes after intervention compared to Group $2(p<0.01)$. Furthermore, the patients with low EOS\% had significantly greater levels of peak troponin I. In addition, the incidence of CIN was greater in Group 1. The rates of inhospital mortality and MACE were significantly higher in Group 1 compared to Group 2 (4\% vs. $1.1 \%, 32.8 \%$ vs. $11.3 \% ; p<0.01$ and $p<0.01)$.

The univariate associates of MACE were taken into multivariate logistic regression analysis. The independent predictors of MACE were shown in Table III. According to multivariate logistic regression analyses: increased age, male sex, the presence of DM, high CRP, low LVEF, unsuccessful PCI, Killip class 3/4, and low EOS\% were found to be independent predictors of MACE in patients with STEMI who underwent PCI. Hosmer-Lemeshow test showed that our model fit the data well $(p=0.21)$.

\section{Discussion}

This study analyzed the association between EOS\% and inhospital outcomes in STEMI patients who underwent primary PCI. Our main finding was that along with advanced age, male sex, the presence of Killip class $3 / 4$, unsuccessful PCI, low LVEF, presence of DM, and high $\mathrm{CRP}$, low EOS\% independently predicted the MACE.

Acute myocardial infarction (AMI)-induced systemic inflammatory response is complex and involves several different blood cell types and different plasma inflammatory mediators. Peripheral markers of this response are accepted as predictors of adverse clinical outcomes and 
Güner et al.

Table I Comparison of demographic, clinical, and laboratory parameters of the groups according to the presence of MACE

\begin{tabular}{|c|c|c|c|c|}
\hline Parameters & All patients $(N=1,909)$ & $\operatorname{MACE}(+)(N=380)$ & $\operatorname{MACE}(-)(N=1,529)$ & $p$ value \\
\hline Age (years) & $54.4 \pm 12.6$ & $58.3 \pm 11.6$ & $53.4 \pm 12.5$ & 0.023 \\
\hline Gender: male $[n(\%)]$ & $1,552(81.3)$ & $327(86.1)$ & $1225(80.1)$ & 0.006 \\
\hline Hypertension $[n(\%)]$ & $484(25.4)$ & $112(29.5)$ & $372(24.3)$ & 0.039 \\
\hline Diabetes mellitus $[n(\%)]$ & $530(27.7)$ & $127(33.4)$ & $403(26.4)$ & 0.004 \\
\hline Dyslipidemia $[n(\%)]$ & $503(26.3)$ & $101(26.6)$ & $402(26.3)$ & 0.897 \\
\hline Smoking $[n(\%)]$ & $599(31.4)$ & $109(28.7)$ & $490(32.0)$ & 0.206 \\
\hline Killip class 3 or $4[n(\%)]$ & $50(2.6)$ & $19(5.0)$ & $31(2.0)$ & 0.001 \\
\hline PCI history $[n(\%)]$ & $327(17.1)$ & $79(20.8)$ & $248(16.2)$ & 0.034 \\
\hline CABG history $[n(\%)]$ & $45(2.3)$ & $15(3.9)$ & $30(2.0)$ & 0.023 \\
\hline Hemoglobin $(\mathrm{g} / \mathrm{dl})$ & $13.6 \pm 1.6$ & $13.5 \pm 1.5$ & $13.7 \pm 1.6$ & 0.129 \\
\hline WBC count $\left(10^{3} / \mu \mathrm{l}\right)$ & $12.2 \pm 4.6$ & $12.6 \pm 4.3$ & $12.1 \pm 4.1$ & 0.087 \\
\hline Neutrophil percentage (\%) & $72.6 \pm 11.5$ & $72.9 \pm 10.9$ & $72.5 \pm 11.9$ & 0.112 \\
\hline Lymphocyte percentage (\%) & $19.8 \pm 3.7$ & $19.6 \pm 3.6$ & $19.8 \pm 3.6$ & 0.345 \\
\hline Monocyte percentage (\%) & $5.9 \pm 1.4$ & $5.8 \pm 1.3$ & $5.9 \pm 1.1$ & 0.478 \\
\hline Eosinophil percentage (\%) & $1.19 \pm 0.34$ & $0.94 \pm 0.13$ & $1.24 \pm 0.63$ & $<0.001$ \\
\hline Basophil percentage (\%) & $0.7 \pm 0.4$ & $0.6 \pm 0.3$ & $0.7 \pm 0.4$ & 0.241 \\
\hline Platelet count $\left(10^{3} / \mu \mathrm{l}\right)$ & $249.2 \pm 78.5$ & $247.5 \pm 81.4$ & $249.6 \pm 63.8$ & 0.239 \\
\hline MPV (fL) & $8.9 \pm 1.4$ & $9.1 \pm 1.3$ & $8.8 \pm 1.5$ & 0.745 \\
\hline Total cholesterol $(\mathrm{mg} / \mathrm{dl})$ & $179.1 \pm 44.5$ & $175.6 \pm 46.9$ & $179.9 \pm 43.5$ & 0.349 \\
\hline $\operatorname{LDL}(\mathrm{mg} / \mathrm{dl})$ & $109.5 \pm 37.9$ & $107.6 \pm 38.9$ & $109.9 \pm 33.7$ & 0.257 \\
\hline $\mathrm{HDL}(\mathrm{mg} / \mathrm{dl})$ & $34.5 \pm 10.1$ & $34.1 \pm 9.3$ & $34.6 \pm 11.5$ & 0.789 \\
\hline Triglyceride (mg/dl) & $158.4 \pm 92.3$ & $155.6 \pm 93.7$ & $159.1 \pm 89.5$ & 0.235 \\
\hline Creatinine $(\mathrm{mg} / \mathrm{dl})$ & $0.88 \pm 0.35$ & $0.93 \pm 0.22$ & $0.86 \pm 0.43$ & 0.645 \\
\hline $\operatorname{GFR}\left(\mathrm{ml} / \mathrm{min} / 1.73 \mathrm{~m}^{2}\right)$ & $98.2 \pm 33.6$ & $95.7 \pm 32.4$ & $98.8 \pm 35.7$ & 0.283 \\
\hline LVEF (\%) & $46.2 \pm 10.2$ & $35.3 \pm 9.7$ & $48.9 \pm 11.8$ & $<0.001$ \\
\hline Peak troponin I (ng/dl) & $33.6 \pm 18.2$ & $34.7 \pm 19.8$ & $33.3 \pm 15.3$ & 0.219 \\
\hline $\mathrm{CRP}(\mathrm{mg} / \mathrm{L})$ & $5.2 \pm 2.6$ & $7.9 \pm 3.9$ & $4.5 \pm 2.2$ & $<0.001$ \\
\hline \multicolumn{5}{|l|}{ Culprid artery } \\
\hline $\operatorname{LAD}[n(\%)]$ & $825(43.2)$ & $158(41.6)$ & $667(43.6)$ & 0.508 \\
\hline $\mathrm{CX}[n(\%)]$ & $290(15.2)$ & $55(14.5)$ & $235(15.4)$ & \\
\hline $\operatorname{RCA}[n(\%)]$ & $686(35.9)$ & $140(36.8)$ & $546(35.7)$ & \\
\hline Others $[n(\%)]$ & $108(56.6)$ & $27(7.1)$ & $81(5.3)$ & \\
\hline Multivessel disease $[n(\%)]$ & $368(19.3)$ & $87(22.9)$ & $281(18.4)$ & 0.046 \\
\hline Stent length (mm) & $9.9 \pm 0.3$ & $9.7 \pm 0.4$ & $9.9 \pm 0.3$ & 0.648 \\
\hline Stent size $(\mathrm{mm})$ & $2.5 \pm 1.3$ & $2.6 \pm 1.4$ & $2.5 \pm 1.2$ & 0.875 \\
\hline Unsuccessful PCI $[n(\%)]$ & $137(7.2)$ & $43(11.3)$ & $94(6.1)$ & $<0.001$ \\
\hline $\mathrm{CIN}[n(\%)]$ & $125(6.5)$ & $34(8.9)$ & $91(6.0)$ & 0.034 \\
\hline Hemodialysis for CIN $[n(\%)]$ & $13(0.7)$ & $3(0.8)$ & $10(0.7)$ & 0.774 \\
\hline
\end{tabular}

CABG: coronary artery bypass graft surgery; CIN: contrast-induced nephropathy; CRP: C-reactive protein; CX: circumflex artery; LVEF: left ventricular ejection fraction; GFR: glomerular filtration rate; HDL: high-density lipoprotein; LAD: left anterior descending artery; LDL: low-density lipoprotein; MACE: major adverse cardiac events, MPV: mean platelet volume; PCI: percutaneous coronary intervention; RCA: right coronary artery; TG: triglyceride; WBC: white blood cell 


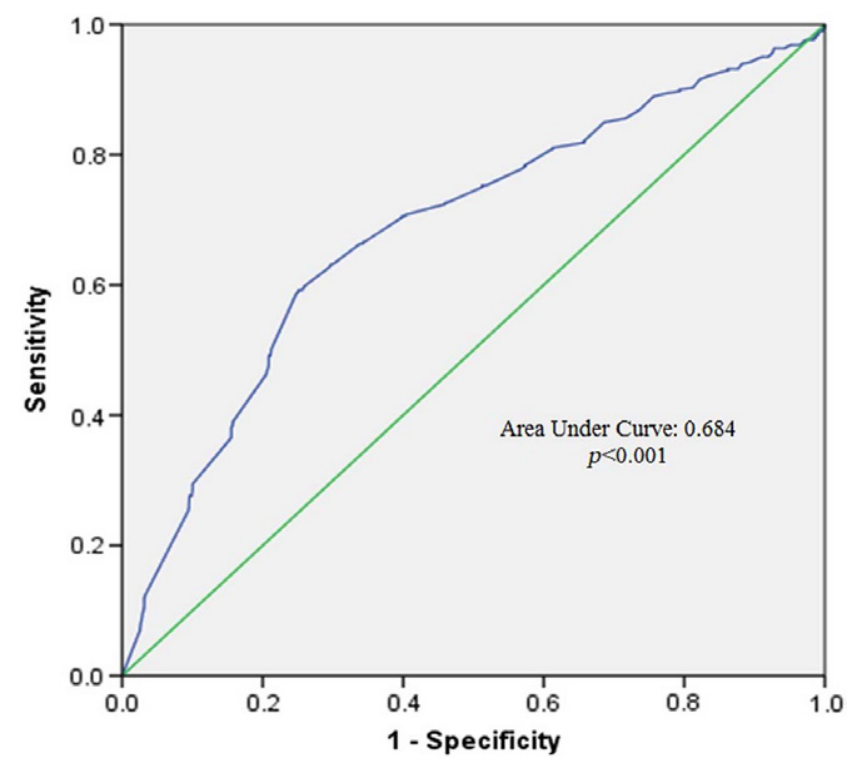

Fig. 1. Receiver operating characteristic curve and area under the curve showing the ability of eosinophil percentage to predict major adverse cardiac events in patients with ST-segment elevation myocardial infarction

found valuable in risk stratification of patients with AMI [18]. Of those inflammatory markers, CRP has been extensively investigated. Accordingly, we have found that higher levels of CRP on admission were independently correlated with inhospital MACE.

Recently, EOSs have gained much more attraction. They play a major role in thrombogenesis, inflammation, and endothelial damage [19]. They are endowed with different granules containing specific molecules released upon activation by an immune provocation. Stimulation of the coagulation pathway, platelet activation and aggregation, endothelial dysfunction, vasoconstriction, and direct induction of thrombus formation are some effects of those candidate molecules [20]. Namely, tissue factor either directly secreted from EOS or exposed on endothelial cells consequent to EOS peroxidase stimulation is accused for occlusions in arterial system. EOS and their granule proteins were detected within the necrotic and thrombotic lesions in the endocardium and in the walls of small blood vessels. Clinical manifestations of these procoagulant and prothrombotic issues are well described in patients with peripheral eosinophilia such as hypereosinophilic syndromes [21, 22]. Furthermore, relatively high peripheral EOS content has been found in patient with vasospastic angina, unstable angina pectoris, instent restenosis, coronary slow flow, and syndrome X [23-27]. After 20 years of follow-up, EOS level was significantly associated with increased risk of future cardiovascular events, and EOS cationic protein was defined as a new biomarker of coronary atherosclerosis [28]. Accumulating evidence provided EOS to be an independent predictor for both the development of clinically significant atherosclerosis and for adverse outcome in patients with symptomatic coronary artery disease. Nevertheless, their role in high-risk patients has not been evaluated yet. Although peripheral eosinophilia favors thrombosis, smooth muscle spasm, and inflammation, circulating EOS numbers significantly decrease under stress and acute inflammation, but granule proteins such as EOS cationic protein may increase in blood. During inflammatory states without a corresponding eosinophilia, EOS localizes in inflammatory lesions and disintegrates and releases their content. Hällgren et al. [29] showed that blood EOS count decreased but EOS derived-factors increased in serum during early phase of AMI. Although the exact mechanisms responsible for the disappearance of EOS from the peripheral blood were not fully understood, attraction of EOS to inflamed endothelium and degradation in thrombus constitute potential underlying mechanisms.

Platelet activation following plaque disruption together with entrapment of circulating blood cells by fibrin network allowing growth of thrombus is considered the basic process for coronary arterial thrombosis leading to STEMI [30]. The analysis of thrombotic material obtained from the patients with acute coronary syndrome revealed EOS between fibrin nets, which were considered to play an important role in promoting thrombus growth [31]. Furthermore, eosinophilic granules but not EOS were detected in atheroma fragments. Jiang et al. found lower peripheral EOS counts and percentages in patients with AMI when compared with stable patients and explained this difference by demonstrating EOS infiltration in coronary arterial thrombi specimens in patients with AMI. Furthermore, they suggested that the decreased EOS\% was inversely correlated with troponin I levels, which indicated serious myocardial damage [10]. In this study, we have found higher peak troponin I levels and lower LVEF in the low EOS\% group. This is the first study to evaluate the role of EOS\% on MACE in patients with STEMI who underwent primary PCI. Our findings are consistent with the findings reported by Jiang et al. and one step forward showing the clinical usefulness of EOS\%. However, Verdoia et al. [32] stated that EOS levels were not associated with development of AMI and no role of EOS was confirmed for myonecrosis after PCI, but they evaluated only stable patients. STEMI and hemodinamically unstable patients requiring urgent angioplasty were excluded. In another study, preprocedural EOS count predicted all-cause mortality only after 6 months following PCI. Furthermore, within 6 months after PCI, mortality reduction was observed in patients with higher EOS levels [33]. Although they focused on low- to intermediate-risk patients undergoing PCI and accepted STEMI as exclusion criteria, our findings overlap with theirs. We have found lower inhospital MACE rate in high EOS\% group. Association of low EOS levels with worse outcome and high EOS levels with better 
Güner et al.

Table II Comparison of demographic, clinical, and laboratory parameters of the groups according to the eosinophil percentage

\begin{tabular}{|c|c|c|c|}
\hline Parameters & $\begin{array}{c}\text { Group } 1 \\
\text { EOS\% } \leq 0.60(N=773)\end{array}$ & $\begin{array}{c}\text { Group 2 } \\
\text { EOS\% }>0.60(N=1,136)\end{array}$ & $p$ value \\
\hline Age (years) & $53.8 \pm 13$ & $54.8 \pm 12$ & 0.114 \\
\hline Gender: male $[n(\%)]$ & $613(79.3)$ & $939(82.6)$ & 0.112 \\
\hline Hypertension $[n(\%)]$ & $184(23.8)$ & $300(26.4)$ & 0.225 \\
\hline Diabetes mellitus [ $n(\%)]$ & $223(28.8)$ & $307(27)$ & 0.328 \\
\hline Dyslipidemia $[n(\%)]$ & $187(24.2)$ & $316(27.8)$ & 0.917 \\
\hline Smoking $[n(\%)]$ & $222(28.7)$ & $377(33.2)$ & 0.043 \\
\hline Killip class 3 or $4[n(\%)]$ & $34(4.4)$ & $16(1.4)$ & $<0.001$ \\
\hline PCI history $[n(\%)]$ & $145(18.7)$ & $182(16)$ & 0.103 \\
\hline CABG history $[n(\%)]$ & $13(1.7)$ & $32(2.8)$ & 0.109 \\
\hline Hemoglobin $(\mathrm{g} / \mathrm{dl})$ & $13.5 \pm 1.7$ & $13.6 \pm 1.6$ & 0.121 \\
\hline WBC count $\left(10^{3} / \mu \mathrm{l}\right)$ & $12.7 \pm 4.6$ & $11.8 \pm 4.6$ & $<0.001$ \\
\hline Neutrophil percentage (\%) & $73.2 \pm 10.3$ & $72.2 \pm 10.8$ & 0.097 \\
\hline Lymphocyte percentage (\%) & $19.9 \pm 3.6$ & $19.7 \pm 3.7$ & 0.346 \\
\hline Monocyte percentage (\%) & $5.8 \pm 1.3$ & $5.9 \pm 1.4$ & 0.748 \\
\hline Eosinophil percentage (\%) & $0.35 \pm 0.09$ & $1.66 \pm 0.43$ & $<0.001$ \\
\hline Basophil percentage (\%) & $0.7 \pm 0.4$ & $0.6 \pm 0.3$ & 0.353 \\
\hline Platelet count $\left(10^{3} / \mu \mathrm{l}\right)$ & $258.1 \pm 120.6$ & $243.2 \pm 70.8$ & $<0.001$ \\
\hline MPV (fL) & $9.03 \pm 1.1$ & $8.8 \pm 3.3$ & $<0.001$ \\
\hline Total cholesterol $(\mathrm{mg} / \mathrm{dl})$ & $177.9 \pm 45.2$ & $180 \pm 43.6$ & 0.193 \\
\hline $\mathrm{LDL}(\mathrm{mg} / \mathrm{dl})$ & $108.9 \pm 37.7$ & $109.9 \pm 38.8$ & 0.519 \\
\hline $\mathrm{HDL}(\mathrm{mg} / \mathrm{dl})$ & $38.6 \pm 10.1$ & $31.8 \pm 10.1$ & 0.202 \\
\hline Triglyceride (mg/dl) & $152.9 \pm 88.1$ & $162.2 \pm 103.5$ & 0.093 \\
\hline Creatinine $(\mathrm{mg} / \mathrm{dl})$ & $0.9 \pm 0.30$ & $0.88 \pm 0.77$ & 0.478 \\
\hline $\operatorname{GFR}\left(\mathrm{ml} / \mathrm{min} / 1.73 \mathrm{~m}^{2}\right)$ & $97.3 \pm 33.9$ & $98.9 \pm 34.9$ & 0.379 \\
\hline $\operatorname{LVEF}(\%)$ & $45 \pm 10.1$ & $47.1 \pm 10.3$ & $<0.001$ \\
\hline Peak troponin I (ng/dl) & $35.4 \pm 17.7$ & $32.3 \pm 18.3$ & $<0.001$ \\
\hline $\mathrm{CRP}(\mathrm{mg} / \mathrm{L})$ & $6.7 \pm 3.4$ & $4.2 \pm 3.9$ & $<0.001$ \\
\hline \multicolumn{4}{|l|}{ Culprid artery } \\
\hline $\operatorname{LAD}[n(\%)]$ & $348(45)$ & $477(42)$ & 0.811 \\
\hline $\mathrm{CX}[n(\%)]$ & $104(13.5)$ & $186(16.4)$ & \\
\hline $\mathrm{RCA}[n(\%)]$ & $245(31.7)$ & $441(38.8)$ & \\
\hline Others $[n(\%)]$ & $76(9.8)$ & $32(2.8)$ & \\
\hline Multivessel disease $[n(\%)]$ & $148(19.1)$ & $220(19.4)$ & 0.952 \\
\hline Stent length $(\mathrm{mm})$ & $10.1 \pm 0.36$ & $9.7 \pm 0.29$ & 0.113 \\
\hline Stent size $(\mathrm{mm})$ & $2.5 \pm 1.2$ & $2.5 \pm 1.5$ & 0.881 \\
\hline Unsuccessful PCI $[n(\%)]$ & $73(9.4)$ & $64(5.6)$ & 0.002 \\
\hline CIN $[n(\%)]$ & $63(8.2)$ & $62(5.5)$ & 0.023 \\
\hline Hemodialysis for CIN $[n(\%)]$ & $8(1)$ & $5(0.4)$ & 0.121 \\
\hline $\operatorname{MACE}[n(\%)]$ & $252(32.6)$ & $128(11.3)$ & $<0.001$ \\
\hline Mortality $[n(\%)]$ & $31(4)$ & $12(1.1)$ & $<0.001$ \\
\hline
\end{tabular}

CABG: coronary artery bypass graft operation; CIN: contrast-induced nephropathy; CRP; C reactive protein; CX: circumflex artery; LVEF: left ventricular ejection fraction; EOS\%: eosinophil percentage; GFR: glomerular filtration rate; HDL: high-density lipoprotein; LAD: left anterior descending artery; LDL: low-density lipoprotein; MACE: major adverse cardiac events, MPV: mean platelet volume; PCI: percutaneous coronary intervention; RCA: right coronary artery; TG: triglyceride; WBC: white blood cell 
Table III The independent predictors of major adverse cardiac events in the multivariate logistic regression analyses

\begin{tabular}{lcr} 
Parameters & OR [95\% CI] & $p$ value \\
Age & $1.024[1.001-1.048]$ & 0.040 \\
Gender: male & $7.071[2.473-20.222]$ & 0.009 \\
Hypertension & $1.051[0.988-1.173]$ & 0.128 \\
Diabetes mellitus & $5.645[3.252-9.801]$ & 0.008 \\
Killip class 3/4 & $100.341[7.969-126.340]$ & $<0.001$ \\
PCI history & $1.012[0.989-1.032]$ & 0.115 \\
CABG history & $1.064[0.887-1.114]$ & 0.093 \\
Eosinophil percentage & $0.441[0.301-0.646]$ & 0.001 \\
Left ventricular ejection fraction & $0.920[0.894-0.947]$ & 0.005 \\
C-reactive protein & $1.061[1.010-1.155]$ & 0.018 \\
Multivessel disease & $1.112[0.875-1.458]$ & 0.078 \\
Unsuccessful PCI & $4.396[3.200-7.560]$ & $<0.001$ \\
Contrast-induced nephropathy & $1.089[0.879-1.345]$ & 0.117 \\
\hline
\end{tabular}

CABG: coronary artery bypass graft surgery; CI: confidence interval; OR: odds ratio; PCI: percutaneous coronary intervention

outcome demonstrates that EOS actively participates in the inflammatory process and has regulatory role in the resolution of acute inflammation.

Determination of the severity of hemodynamic impairment on admission using the Killip classification was defined as an independent prognostic factor for adverse events in patients with STEMI [34]. In our cohort, the patients in low EOS\% group had higher Killip class (3/4), which was independently related to inhospital MACE. In accordance with previous reports, we found unsuccessful reperfusion to be an independent predictor of unfavorable clinical outcomes [35].

Some limitations of this study should be taken into account. First, since EOS have important role in thrombus formation and expansion, large thrombus burden in low EOS\% group may be the factor that limits the effectiveness of infarct-related artery reopening and enhances the extent of myocardial necrosis. However, we did not evaluate intracoronary thrombus burden in our patients. Second, we evaluated predictive role of EOS\% but not peripheral EOS count. Previous studies pointed out that, within EOS indices, only decreased EOS\% indicated serious myocardial damage, and EOS count was very low to be measured in some patients. Third, we presented a single-center experience and used only EOS\% on admission and did not evaluate serial levels during follow-up. Finally, we did not have data regarding longterm follow-up of our patients.

\section{Conclusion}

In conclusion, this study confirmed the important role of EOS in patients with STEMI who underwent primary
PCI. We demonstrated that low admission preprocedural EOS\% was significantly associated with inhospital MACE in these patients. EOS\% may be a novel biomarker for risk stratification in patients with STEMI. The prognostic significance of our findings should be investigated in future trials.

Funding sources: No financial funding was received for this study.

Authors' contribution: All the authors contributed planning, conduct, and reporting of the work. They had full access to all data in the study and take responsibility for the integrity of the data and the accuracy of the data analysis.

Conflict of interest: All authors declare no conflict of interest.

\section{References}

1. Han Y, Jing J, Tu S, Tian F, Xue H, Chen W, Chen J, Reiber JH, Chen Y: ST elevation acute myocardial infarction accelerates nonculprit coronary lesion atherosclerosis. Int J Cardiovasc Imaging 30, 253-261 (2014)

2. Libby P: Mechanisms of acute coronary syndromes and their implications for therapy. N Engl J Med 368, 2004-2013 (2013)

3. Mezzaroma E, Toldo S, Farkas D, Seropian IM, Van Tassell BW, Salloum FN, Kannan HR, Menna AC, Voelkel NF, Abbate A: The inflammasome promotes adverse cardiac remodeling following acute myocardial infarction in the mouse. Proc Natl Acad Sci U S A 108, 19725-19730 (2011)

4. Rohrbach MS, Wheatley CL, Slifman NR, Gleich GJ: Activation of platelets by eosinophil granule proteins. J Exp Med 172, 1271-1274 (1990)

5. Fujita K, Ishimaru H, Hatta K, Kobashi Y: Hypereosinophilic syndrome as a cause of fatal thrombosis: Two case reports with histological study. J Thromb Thrombolysis 40, 255-259 (2015) 
6. Mactier I, Dalzell JR, Carrick D: Recurrent myocardial infarction in a 50-year-old woman. Heart 105 (2019)

7. Trivedi SJ, Tanous D, Suan D: Coronary artery vasospasm in a patient with Churg-Strauss syndrome. BMJ Case Rep 2018, pii: bcr-2018-225321 (2018)

8. Chai JT, McGrath S, Lopez B, Dworakowski R: Eosinophilic granulomatosis with polyangiitis (Churg-Strauss syndrome) masquerading as acute ST-elevation myocardial infarction with complete resolution after immunosuppressive therapy: A case report. Eur Heart J Case Rep 2, yty075 (2018)

9. Avramakis G, Papadimitraki E, Papakonstandinou D, Liakou K, Zidianakis M, Dermitzakis A, Mikhailidis DP, Ganotakis ES: Platelets and white blood cell subpopulations among patients with myocardial infarction and unstable angina. Platelets 18, 16-23 (2007)

10. Jiang P, Wang DZ, Ren YL, Cai JP, Chen BX: Significance of eosinophil accumulation in the thrombus and decrease in peripheral blood in patients with acute coronary syndrome. Coron Artery Dis 26, 101-106 (2015)

11. Rios-Navarro C, Gavara J, Vidal V, Bonanad C, Racugno P, Bayes-Genis A, Miñana G, Husser O, Oltra R, Nuñez J, Chorro FJ, Bodi V, Ruiz-Sauri A: Characterization and implications of the dynamics of eosinophils in blood and in the infarcted myocardium after coronary reperfusion. PLoS One 13, e0206344 (2018)

12. Levey AS, Bosch JP, Lewis JB, Greene T, Rogers N, Roth D: A more accurate method to estimate glomerular filtration rate from serum creatinine: A new prediction equation. Modification of Diet in Renal Disease Study Group. Ann Intern Med 130, 461-470 (1999)

13. Stone NJ, Robinson JG, Lichtenstein AH, Bairey Merz CN, Blum $\mathrm{CB}$, Eckel RH, Goldberg AC, Gordon D, Levy D, Lloyd-Jones DM, McBride P, Schwartz JS, Shero ST, Smith SC Jr, Watson K, Wilson PW, Eddleman KM, Jarrett NM, LaBresh K, Nevo L, Wnek J, Anderson JL, Halperin JL, Albert NM, Bozkurt B, Brindis RG, Curtis LH, DeMets D, Hochman JS, Kovacs RJ, Ohman EM, Pressler SJ, Sellke FW, Shen WK, Smith SC Jr, Tomaselli GF: 2013 ACC/AHA guideline on the treatment of blood cholesterol to reduce atherosclerotic cardiovascular risk in adults: A report of the American College of Cardiology/American Heart Association Task Force on Practice Guidelines. J Am Coll Cardiol 63, 2889-2934 (2014)

14. Mehran R, Nikolsky E: Contrast-induced nephropathy: Definition, epidemiology, and patients at risk. Kidney Int Suppl 100, 11-15 (2006)

15. Glud T, Schmidt EB, Kristensen SD, Arnfred T: Platelet number and volume during myocardial infarction in relation to infarct size. Acta Med Scand 220, 401-405 (1986)

16. Sianos G, Papafaklis MI, Serruys PW: Angiographic thrombus burden classification in patients with ST-segment elevation myocardial infarction treated with percutaneous coronary intervention. J Invasive Cardiol 22, 6-14 (2010)

17. Thygesen K, Alpert JS, Jaffe AS, Chaitman BR, Bax JJ, Morrow DA, White HD: Executive Group on behalf of the Joint European Society of Cardiology (ESC)/American College of Cardiology (ACC)/American Heart Association (AHA)/World Heart Federation (WHF) Task Force for the Universal Definition of Myocardial Infarction. Fourth universal definition of myocardial infarction. J Am Coll Cardiol 72, 2231-2264 (2018)

18. Nanchen D, Klingenberg R, Gencer B, Räber L, Carballo D, von Eckardstein A, Windecker S, Rodondi N, Lüscher TF, Mach F, Muller $\mathrm{O}$, Matter CM: Inflammation during acute coronary syndromes - Risk of cardiovascular events and bleeding. Int J Cardiol 287, 13-18 (2019)
19. Konishi T, Funayama N, Yamamoto T, Morita T, Hotta D, Nishihara H, Tanaka S: Prognostic value of eosinophil to leukocyte ratio in patients with ST-elevation myocardial infarction undergoing primary percutaneous coronary intervention. J Atheroscler Thromb 24, 827-840 (2017)

20. Ames PR, Margaglione M, Mackie S, Alves JD: Eosinophilia and thrombophilia in Churg Strauss syndrome: A clinical and pathogenetic overview. Clin Appl Thromb Hemost 16, 628-636 (2010)

21. Ogbogu PU, Rosing DR, Horne MK: Cardiovascular manifestations of hypereosinophilic syndromes. Immunol Allergy Clin North Am 27, 457-475 (2007)

22. Jin X, Ma C, Liu S, Guan Z, Wang Y, Yang J: Cardiac involvements in hypereosinophilia-associated syndrome: Case reports and a little review of the literature. Echocardiography 34, 1242-1246 (2017)

23. Umemoto S, Suzuki N, Fujii K, Fujii A, Fujii T, Iwami T, Ogawa H, Matsuzaki M: Eosinophil counts and plasma fibrinogen in patients with vasospastic angina pectoris. Am J Cardiol 85, 715-719 (2000)

24. Erdogan O, Gul C, Altun A, Ozbay G: Increased immunoglobulin E response in acute coronary syndromes. Angiology 54, 73-79 (2003)

25. Cook S, Ladich E, Nakazawa G, Eshtehardi P, Neidhart M, Vogel R, Togni M, Wenaweser P, Billinger M, Seiler C, Gay S, Meier B, Pichler WJ, Jüni P, Virmani R, Windecker S: Correlation of intravascular ultrasound findings with histopathological analysis of thrombus aspirates in patients with very late drug-eluting stent thrombosis. Circulation 120, 391-399 (2009)

26. Demir M, Şentürk M, Kuzeytemiz M: The relationship between eosinophil and cardiac syndrome X. Clin Appl Thromb Hemost 21, 325-328 (2015)

27. Altas Y, Kurtoglu E, Yaylak B, Baysal E, Ucaman B, Ugurlu HM, Karahan MZ, Altintas B, Adiyaman MS, Kaya İ, Erdolu U, Ozen K, Cakir C, Sevuk U: The relationship between eosinophilia and slow coronary flow. Ther Clin Risk Manag 11, 1187-1191 (2015)

28. Hou L, Lloyd-Jones DM, Ning H, Huffman MD, Fornage M, He K, Zhang X, Jacobs DR, Goff DC, Sidney S, Carr JJ, Liu K: White blood cell count in young adulthood and coronary artery calcification in early middle age: Coronary Artery Risk Development in Young Adults (CARDIA) study. Eur J Epidemiol 28, 735-742 (2013)

29. Hällgren R, Venge P, Cullhed I, Olsson I: Blood eosinophils and eosinophil cationic protein after acute myocardial infarction or corticosteroid administration. Br J Haematol 42, 147-154 (1979)

30. Guner A, Hakgor A, Gunduz S, Aksoy R, Havan N, Ocal L, Celik M, Bayam E, Ozkan M: Thrombosis of giant coronary aneurysms presenting as ST-elevation myocardial infarction. Coron Artery Dis 29, 174-176 (2018)

31. Sakai T, Inoue S, Matsuyama TA, Takei M, Ota H, Katagiri T, Koboyashi $\mathrm{Y}$ : Eosinophils may be involved in thrombus growth in acute coronary syndrome. Int Heart J 50, 267-277 (2009)

32. Verdoia M, Schaffer A, Barbieri L, Sinigaglia F, Marino P, Suryapranata H, De Luca G, Novara Atherosclerosis Study Group (NAS): Eosinophils count and periprocedural myocardial infarction in patients undergoing percutaneous coronary interventions. Atherosclerosis 236, 169-174 (2014)

33. Toor IS, Jaumdally R, Lip GY, Millane T, Varma C: Eosinophil count predicts mortality following percutaneous coronary intervention. Thromb Res 130, 607-611 (2012)

34. Mello BH, Oliveira GB, Ramos RF, Lopes BB, Barros CB, Carvalho Ede O, Teixeira FB, Arruda GD, Revelo MS, Piegas LS: Validation of the Killip-Kimball classification and late mortality after acute myocardial infarction. Arq Bras Cardiol 103, 107-117 (2014)

35. Napodano M, Dariol G, Al Mamary AH, Marra MP, Tarantini G, D’Amico G, Frigo AC, Buja P, Razzolini R, Iliceto S: Thrombus burden and myocardial damage during primary percutaneous coronary intervention. Am J Cardiol 113, 1449-1456 (2014) 